\title{
Parents should declare children's vaccine status, doctors say
}

$\mathrm{P}$ arents should present a declaration of immunization status to school officials and if their children are inadequately immunized, they should consult with public health officials. That was the unanimous decision of delegates at the Canadian Medical Association (CMA) General Council on Aug. 25.

The motion addresses parents who aren't against vaccination, but who are "vaccine hesitant and have questions and concerns that need to be addressed before making a decision about vaccinating their child," said Dr. Chris Simpson, CMA past president.

"The goal is not to make vaccination compulsory," stressed the mover Dr. Yun Jen, President of the Québec Medical Association, "but to make available the provision of important information about managing infectious diseases through vaccination. We believe with this measure we can improve protection."

Simpson pointed to studies in the United States, which have indicated that making it more difficult for parents to exempt their child deters most from obtaining an exemption.

"Effective interaction can address concerns ... and motivate hesitant parents toward immunization," added CMA President Dr. Cindy Forbes. Mandatory immunization wouldn't improve rates, she added: "It kind of inflames the conversation."

However, locating a child's information on vaccine status can be problematic, Forbes admitted, which is why a national registry of immunization is "essential." This could be spearheaded by the federal government or by an alliance of provinces. Such a registry would provide a comprehensive way to keep records, would allow for earlier identification of problems and should improve uptake, said Forbes.

Delegates approved a resolution to accelerate development and implementation of a national immunization registry at the meeting. They also gave the nod to motions to develop a national

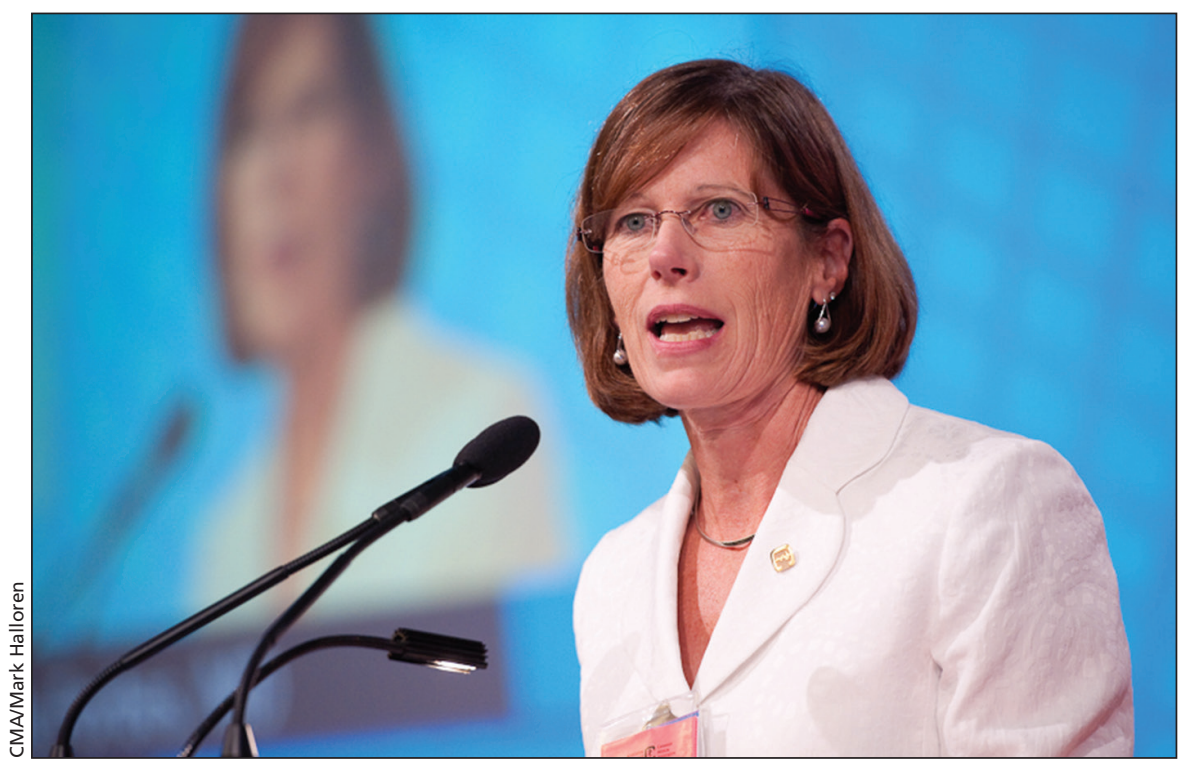

A national registry of immunization is "essential," said CMA President Dr. Cindy Forbes.

vaccine hesitancy plan and to reduce barriers to accessing immunization, and for government to step up its commitment to promoting and raising awareness of immunization against childhood diseases.

However, delegates stopped short of suggesting that compensation should be provided for people who suffer the rare debilitating injuries associated with vaccination. They overwhelmingly rejected the motion put forward by Dr. Denis Yahiaoui of Montréal. He argued that people get vaccines to protect themselves and their community, so when they experience a debilitating injury, the community should help them.

Canada and Russia are the only G8 countries without such a compensation program. Quebec does have one, but elsewhere in Canada those seeking compensation must go to civil court. However, civil courts compensate based on negligence and given that best practices in immunization are typically followed, there have not been any awards.

Pediatrician and vaccine expert Noni MacDonald countered that the Quebec program, which has been in place for 20 years, has made no differ- ence in terms of vaccine acceptance relative to the rest of Canada.

But compensation programs can help people who are affected, said Dr. Jane Brooks, from Middleton, Nova Scotia. When her brother became deaf after receiving the mumps-measles-rubella vaccine, her parents were unable to afford a hearing aid for three years. "There are many people who would benefit as my brother would have."

Other delegates were concerned that a compensation program might open the doors for compensation for other policies aimed at the public good. For example, Dr. Lloyd Oppel of Vancouver, pointed to seat belt legislation. "Seat belts sometimes harm people: Should they be compensated?" he asked.

"Nothing is perfect," said Dr. Pierre Harvey, Rivière-du-Loup, Quebec, who seconded the motion. CMA wants to reduce obstacles to vaccination, and for some people, the lack of compensation for injury could be seen as an obstacle. "Without the program some people may decide not to get immunized."

The motion failed, $27 \%$ to $70 \%$. Barbara Sibbald, CMAJ

CMAJ 2015. DOI:10.1503/cmaj.109-5143 